\title{
CRIMSONpublishers
}

\author{
http://www.crimsonpublishers.com
}

Opinion

Gerontol \& Geriatric stud

ISSN 2578-0093

\section{Losing the art of taking care of the elderly...............to be researched, revived and inculcated}

\author{
Padma Harshan PhD \\ Founder Director of SHWEF, India \\ *Corresponding author: Padma Harshan PhD, Founder Director of SHWEF, India
}

Submission: 眥 August 28, 2017; Published: 㘹 October 06, 2017

\section{Opinion}

Life in earlier days was much better, environment friendly, easier and with lots of love, respect and care for others too, changing lifestyles, eating habits, demanding environment more attachment to worldly things has changed the entire life cycle of a normal average family who once valued the joint family culture in India. Now the trend is of nuclear family that has worsened the interaction of grandchildren with grandparents and hence the fragile balance of respect, love, needs, feelings, and emotions is seen evading. Communicating through stories that usually carried some lessons, moral values, discipline, and good food habits with grandchildren was a past time for the grandparents, now their place has been taken by all electronic gadgets and spoiled their daily routine thereby their mental and physical health too.

Mothers are the pillars of the family and the very first teacher to her children, the growing living demand has forced her to step out for work. The ever increasing outside work pressure has made her highly stressed to look into the daily affairs of each one in the family and hence her contribution towards the grooming of the kids, imparting cultural and moral values in its true sense is getting dissolved thus making the situation little un-conducive for a healthy relations among everybody. In the process we as individuals have started losing the ways and gentle art of taking care of the elderly at our homes and unknowingly transmitting that nature to our kids. Such behaviors are leading to tensions in the family resulting ignoring them or by some admitting parents to old age homes.

Encouraging spirituality through regular morning and evening prayers was a regular feature now it's not seen or it's just a formality of lighting the lamp. Dining together was also a common feature, now all these processes are things of the past that once use to bind the family members. Fewer interactions, talks or an advice with the elders has created confusion in their minds-that does their presence really matter? This leads them to a state of aloofness, isolation and later depression with deterioration of physical conditions. Excess use of smart phones is leading to an abnormal and unhealthy life to each one in the family.

Outmigration for jobs from rural places to urban cities is another major cause of worry to people living in rural India thus leaving the old parents to feed for themselves with the help of relatives and neighbors. Their conditions are even worse in terms of mental, emotional, health and physical. We need to inculcate the habit of respecting, taking care of the elders by our children, making them understand how important are they in our life and they are just like sweet little kids to be taken off by all the members to make them smiling, healthy and as a blessing from the Lord to give us the life they had built for us by sacrificing their lives.

Personal observations during counselling/interacting with families wherein a lot of commotion in handling the issues of elderly is concerned 